\title{
¿Qué dijo doctor? Una revisión de términos radiológicos conflictivos
}

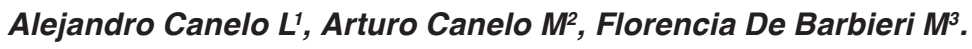

1. Interno de Medicina, Escuela de Medicina, Pontificia Universidad Católica de Chile. Santiago, Chile.

2. Médico Radiólogo. Centros médicos ImagenSalud. San Fernando, Chile.

3. Médica Radióloga. Departamento de Radiología y Diagnóstico por Imágenes, Pontificia Universidad Católica de Chile. Santiago, Chile.

\section{What did you say, doctor? A review of conflictive radiological terminology}

\section{Resumen}

La terminología médica del idioma español es la herramienta mediante la cual un profesional de la salud puede comunicar una idea de forma precisa y correcta a sus colegas. El abanico de tecnicismos en radiología es amplio, creando dudas sobre la forma exacta de escribir y usar un concepto en particular. El objetivo de este trabajo es resolver la incertidumbre que producen algunas palabras y conceptos. En total se analizaron 11 términos y construcciones verbales, eligiendo para cada uno de ellos la forma más correcta. Palabras clave: Comunicación interdisciplinaria; Escritura médica; Radiología.

\begin{abstract}
The medical terminology of the Spanish language is the main tool by which a health professional can communicate with colleagues in a precise and correct manner. The technical terms spectrum in radiology is wide, arising doubts on the exact way of writing and using a particular concept. The purpose of this work is to solve the uncertainty that some words and concepts produce. In total, 11 terms and verbal constructions were analyzed, choosing the most correct form for every one of them.

Keywords: Interdisciplinary communication; Medical writing; Radiology.
\end{abstract}

Canelo A, et al. ¿Qué dijo doctor? Una revisión de términos radiológicos conflictivos. Rev Chil Radiol 2021; 27(1): 04-07. ${ }^{*}$ Correspondencia: Alejandro Canelo L. / aicanelo@uc.cl

Trabajo enviado el 20 de agosto de 2020. Aceptado para publicación el 20 de octubre de 2020.

\section{Introducción}

El lenguaje médico español se destaca por el uso de términos altamente específicos que describen gran cantidad de estructuras anatómicas, condiciones fisiológicas, patologías y tratamientos, con la intención de mantener una clara e inequívoca comunicación entre los médicos. Resulta así tan técnico, que de manera jocosa se ha culpado a los facultativos de hablar otro idioma. Por si esto fuera poco, constantemente aparecen nuevos términos, epónimos y neologismos originados de nuevas técnicas terapéuticas y diagnósticas, generalmente desde otros idiomas, agregando aún más tecnicismos a la jerga médica.

El médico desea utilizar el lenguaje de manera adecuada, tanto para asegurar una fluida comunicación entre pares como para establecer una marca de su profesionalismo. Esto último se acentúa en especialidades donde el informe escrito es fundamental para su ejercicio, siendo la radiología una de las más relevantes. Tal abundancia de palabras a menudo genera dudas sobre su correcto uso o escritura. Las discrepancias que nacen de sus posibles variantes originan con cierta frecuencia debates entre colegas, y la mayoría de las veces no se logra establecer la forma exacta del término en cuestión.

Dado este contexto, el presente trabajo tiene como objetivo aclarar y dar consejos sobre el uso de algunos de estos términos comúnmente en discusión, especialmente dentro de la Radiología.

Para este trabajo, se optó por incluir términos que en la práctica radiológica sean recurrentes, que posean relevancia para el especialista a la hora de 
transmitir adecuadamente un mensaje, que su forma incorrecta sea ampliamente utilizada y que, por experiencia de los autores, sea motivo de conflicto entre colegas. Otros términos fueron considerados (como por ejemplo "injuria" y "polaquiuria"), pero por motivos de concisión, y por tratarse de conceptos más generales y alejados de la radiología, se excluyeron de esta publicación. Estos vocablos serán reconsiderados en futuras publicaciones. La principal fuente bibliográfica utilizada corresponde a la $23^{\mathrm{a}}$ edición del Diccionario de la lengua española (DLE) de la Real Academia Española (RAE). No obstante, como este diccionario omite algunos términos comunes del lenguaje médico especializado, no debe ser considerado como el único criterio válido ${ }^{1}$. Por esta razón, para completar el análisis se hace también uso de otras obras académicas como el Diccionario de términos médicos (DTM) de la Real Academia Nacional de Medicina (RANM), el Diccionario panhispánico de dudas, la Gramática descriptiva de la lengua española, la última edición de la Nueva gramática de la lengua españolas, otras publicaciones sobre el lenguaje médico español, y en el caso de los extranjerismos, diccionarios y textos médicos de la lengua correspondiente.

\section{¿Imagenología o imaginología?}

Hasta el año 2014, el Diccionario de la lengua española definía "imaginología" como "estudio y utilización clínica de las imágenes producidas por los rayos $\mathrm{X}$, el ultrasonido, la resonancia magnética, etc ${ }^{2 "}$. Sin embargo, en su versión actualizada, esta misma acepción pasó a la palabra "imagenología", eliminándose "imaginología" del léxico hispánico ${ }^{3}$. El cambio fue seguramente suscitado por el rechazo que sufría este último término por parte de la comunidad profesional, dada su similitud a la raíz de la palabra "imaginar". En conclusión, el término correcto es "imagenología".

\section{¿Proyección de Lauenstein o de Löwenstein?}

En el estudio de la cadera mediante radiografía simple, para referirse a la proyección anteroposterior en "posición de rana" se utilizan comúnmente los epónimos "Lauenstein" o "Löwenstein". Este último es el más frecuente en la literatura tanto española como inglesa. Sin embargo, esta proyección radiológica fue descrita por primera vez en 1901 por el cirujano alemán Carl Lauenstein (1850-1915) ${ }^{5}$, y en la literatura alemana el epónimo "Lauenstein" es el único utilizado ${ }^{6,7}$. Por tanto, se sugiere el abandono de "Löwenstein" y la adopción del término correcto "Lauenstein".

\section{¿Dedo del pie u ortejo?}

Es extensamente utilizado el término "ortejo" para referirse a los dedos de los pies. Esta palabra proviene del francés orteil, cuyo significado es precisamente "cada uno de los cinco dedos del pie". El galicismo "ortejo" llegó a nosotros probablemente a través de traducciones españolas de los libros de medicina o como vestigio de la influencia del francés a comienzos del siglo pasado ${ }^{9}$. A pesar de esto, este vocablo no es reconocido por los diccionarios de la lengua hispánica, pues su uso es innecesario al poseer un equivalente válido en español ("dedo del pie"). Por ende, lo más correcto y acorde a nuestro idioma sería hablar de "dedo del pie" y no de "ortejo".

\section{¿Ecografía o ecotomografía?}

El término "ecotomografía" es usado por algunos como sinónimo de "ecografía". Su origen nace probablemente de la intención de especificar el uso de ecos de ultrasonidos en una técnica de "tomografía", definida como la "técnica de exploración, especialmente radiológica, que permite obtener imágenes de un corte o plano concreto de un cuerpo"3. A pesar de la precisión que agrega el elemento -tomo- (del griego tómos: "corte, sección"), la forma correcta de uso es "ecografía". La palabra "ecotomografía" no está incluida en el vocabulario médico españo| ${ }^{3,4}$.

\section{¿Rotura o ruptura?}

Si bien en el Diccionario de la lengua española la primera acepción para ambos términos es la misma ("acción y efecto de romper o romperse") ${ }^{3}$, estos términos son posteriormente diferenciados en sus definiciones respectivas. Respaldado por el Diccionario panhispánico de dudas y otros trabajos sobre el tema, se prefiere el uso de "rotura" cuanto se trata de realidades materiales o cuerpos sólidos, mientras que se reserva "ruptura" para realidades inmateriales, como las relaciones entre personas ${ }^{10,11}$. De esta manera, se aconseja usar construcciones como "rotura esplénica" y "rotura de tendón" en vez de "ruptura esplénica" y "ruptura de tendón".

\section{¿Complejo ostiomeatal u osteomeatal?}

Existe un canal común que une los orificios de drenaje mucociliar de los senos paranasales frontales, etmoidales anteriores y maxilares dirigido hacia el meato nasal medio, denominado unidad o complejo ostiomeatal ${ }^{12}$. El término "osteomeatal" no es adecuado, puesto que el complejo no hace referencia a las estructuras óseas colindantes, sino a la relación entre el orificio u ostium de drenaje de cada seno y el meato nasal medio. De ahí que "ostiomeatal" provenga de las palabras "ostium" y "meato". Podría argüirse que existe redundancia en el término "ostiomeatal", pues en ocasiones "meato", al igual que "ostium", denota un orificio en la anatomía humana (p. ej., meato urinario). Pero este no es el caso del complejo ostiomeatal, en donde el meato medio corresponde al canal horizontal formado entre el cornete medio y la pared nasal lateral, no a un orificio puntual. 


\section{¿Pectus o pectum excavatum?}

La escritura de "pectus excavatum" se presta fácilmente para confusión, derivando en formas incorrectas como "pectum excavatum" al forzar que el sustantivo ("pectus") y el adjetivo ("excavatum") coincidan en sus terminaciones. En latín, el sustantivo "pectus" pertenece al género neutro, cuyos adjetivos en caso nominativo adoptan la terminación -um. Sabiendo esto, lo correcto y lógico es decir "pectus excavatum".

\section{¿Tiroidea o tiroídea?}

El sufijo -oide /-oides y su variante -oideo /-oidea agregan el significado de "con apariencia de" a la palabra raíz, como por ejemplo en odontoides ("con apariencia de diente") y "tiroideo" ("con apariencia de escudo") ${ }^{3,4,13}$. Estas formas mencionadas son aceptadas por las instituciones oficiales de la lengua hispana. Por otro lado, es muy común oír el sufijo tildado -oídeo /-oídea formando parte de términos médicos, el cual no es mencionado como válido por las obras dedicadas al estudio y normación de nuestro idioma. En consecuencia, debe emplearse "tiroideo" y abandonar el uso de su variante tildada. Se presentan otros ejemplos de la misma índole en la tabla 1.

Tabla 1. Palabras terminadas en -oideo de uso común. Formas correctas e incorrectas.

\begin{tabular}{|ll|}
\hline Correcto & Incorrecto \\
\hline Tiroideo & Tiroídeo \\
Reumatoideo & Reumatoídeo \\
Coroideo & Coroídeo \\
Subaracnoideo & Subaracnoídeo \\
Mastoideo & Mastoídeo \\
Sesamoideo & Sesamoídeo \\
Tifoidea & Tifoídea \\
Adenoideo & Adenoídeo \\
Coloideo & Coloídeo \\
Sigmoideo & Sigmoídeo \\
Xifoideo & Xifoídeo \\
Esteroideo & Esteroídeo \\
Hialoideo & Hialoídeo \\
Hioideo & Hioídeo \\
Lipoideo & Lipoídeo \\
Amiloideo & Amiloídeo \\
Deltoideo & Deltoídeo \\
\hline
\end{tabular}

\section{"Sangramiento" y "velamiento"}

Es habitual encontrar la utilización de estos dos neologismos en la práctica radiológica, formados a partir de los verbos "sangrar" y "velar". El sufijo -miento es uno de los más productivos del idioma español, en cuanto origina una nueva palabra a partir de un verbo, con el sentido de "acción y efecto" de este último. Sin embargo, muchas de estas palabras son creaciones ocasionales y poco extendidas, por lo que no están incluidas en los diccionarios ${ }^{14,15}$. Este es el caso de "sangramiento" y "velamiento". Como reemplazo, es más correcto el término "sangrado" o incluso "hemorragia" para el primer término. Para el segundo, sería recomendable decir que la estructura en cuestión está "velada" (p. ej., "los senos costofrénicos aparecen velados"), ya que los diccionarios no han incluido un vocablo que represente el efecto de "velar" en el sentido de "ocultar".

\section{"Consistente con..."}

Es incorrecto el uso de esta oración en el sentido de compatibilidad o concordancia, como en la frase "hallazgos consistentes con luxación anterior de hombro". Esto corresponde a un anglicismo derivado del adjetivo consistent, que en inglés puede ser sinónimo de "compatible". En español, "consistente" no posee acepciones cercanas a tal concepto ${ }^{3}$. Recomendamos preferir construcciones como "compatible con" o "concordante con".

\section{"Se sugiere descartar..."}

Finalmente, más que resolver una duda gramátical, ofrecemos un consejo aplicable a la hora de redactar un informe radiológico. Es frecuente el uso de la oración "se sugiere descartar..." cuando el informe del radiólogo aconseja al médico tratante realizar otras pruebas diagnósticas, para evaluar la presencia o no de cierta patología o condición en particular. El problema de esta oración reside en que puede llevar a confusión a quien no está familiarizado con el sentido que adopta en la práctica médica. Un abogado, por ejemplo, al leer la frase "se sugiere descartar tromboembolismo pulmonar", podría interpretar que el médico radiólogo está sugiriendo eliminar esta patología de los diagnósticos diferenciales, cuando en realidad recomienda justamente lo contrario: la búsqueda dirigida de tromboembolismo pulmonar mediante otros métodos diagnósticos. El lector comprenderá que esta interpretación errónea por parte de un juez, pero válida dada la sintaxis de la oración, puede llevar al médico informante a situaciones muy complicadas. Por esta razón, es que sugerimos descartar el uso de esta construcción, y reemplazarla con otras como "se sugiere considerar...".

\section{Conclusión}

Junto con una buena práctica de la medicina, el correcto uso del lenguaje médico forma parte del sello de calidad profesional. Se han analizado algunos términos conflictivos en el lenguaje médico, especialmente radiológicos, con el fin de contribuir al perfeccionamiento de la práctica médica en un área a veces negligida. Esperamos que este texto ayude a los médicos a resolver algunas de las dudas 
lingüísticas que surgen en la práctica. Por último, con la intención de realizar en el futuro una nueva compilación en este estilo, invitamos a los lectores a contactar y enviar sus dudas a los autores.

\section{Referencias}

1. Navarro FA. La precisión del lenguaje en la redacción médica. En: Rico-Villademoros F, Alfaro V, (Eds). La redacción médica como profesión: qué es y qué hace el redactor de textos médicos. Barcelona: Fundación Dr. Antonio Esteve. 2009; 89-104.

2. Real Academia Española. Diccionario de la lengua española. 22a ed. Madrid: España; 2001.

3. Real Academia Española. Diccionario de la lengua española. 23a ed. Madrid: España; 2014.

4. Real Academia Nacional de Medicina. Diccionario de términos médicos. 1a ed. Madrid: Editorial Médica Panamericana; 2011.

5. Lauenstein C. Nachweis der "Kocher'schen Verbietung" des Schenkelhalses bei der Coxa vara durch Röntgenstrahlen. Fortschr Geb Röntgenstrahlen. 1901; 4: 61-64.

6. Bernau A. Röntgendiagnostik und Einstelltechniken beim Nativröntgen. En: Wirth CJ, Zichner L, Tschauner C, (Eds). Orthopädie und orthopädische Chirurgie: das Standardwerk für Klinik und Praxis. Becke, Hüfte. 1a ed. Stuttgart: Georg Thieme Verlag. 2004; 61-67.
7. Dudenredaktion (Eds). Duden - Wörterbuch medizinischer Fachbegriffe. 9a ed. Mannheim: Dudenverlag; 2012.

8. Académie française. Dictionnaire de l'Académie française. 9a ed. París, Fayard. 2011. https://www. dictionnaire-academie.fr/article/A900795. (Accesado el 21/Jul/2020).

9. Tamez RM. Hablemos bien y escribamos mejor. Dudas ortográficas de algunos términos médicos. Cir Plast 2003; 13(1): 5-7.

10. Asensi-Pérez J, Villalba-Ferrer F, Roig-Vila JV. El lenguaje médico y quirúrgico. Cir Esp 2008; 84(1): 10-15.

11. Real Academia Española. Diccionario panhispánico de dudas. 1a ed. 2005. https://www.rae.es/dpd/rotura. (Accesado el 22/Jul/2020).

12. Laine FJ, Smoker WR. The ostiomeatal unit and endoscopic surgery: anatomy, variations, and imaging findings in inflammatory diseases. AJR Am J Roentgenol. 1992; 159(4): 849-857.

13. Gallar P. Léxico radiológico conflictivo. 2a ed. A Coruña: Covidien; 2010.

14. Bosque I, Demonte V. Gramática descriptiva de la lengua española. Madrid, España. 1999: vol. 3.

15. Real Academia Española y Asociación de Academias de la Lengua Española. Nueva gramática de la lengua española. Morfología y sintaxis. Madrid: España; 2009. 